\title{
청계천 Cheonggyecheon: Streaming Currere
}

\author{
BARBARA CHANCELLOR \\ RMIT University (Australia)
}

\begin{abstract}
In the following paper I share my personal journey into rhizomatic thinking. Here I illustrate how a rhizome opened new possibilites to my previously confusing learning process. As a vehicle I ask the question, when considering the pedagogical nature of place, how does the new facilitate currere? I am also taking the opportunity to write in a way that is new and unfamiliar to me because the conventional and acceptable have been unable to help me understand the meanings I am seeking. I felt uninspired among traditional styles of academic writing until I encountered the doctoral thesis of Warren Sellers where another way of seeing and writing is explored. This generative experience gave me the momentum to link past learnings in new rhizomatic ways and begin a discussion within this journal about how place and pedagogy connect. My visit to Cheonggyecheon Stream in Seoul provided me the place and my reading of the texts of Warren Sellers, Noel Gough, Chaim Soutine, Margaret Sommerville and Lloyd Rees gave me examples of others who have searched. As I remember my physical experience of this new place, the stream becomes the search, the bridges spanning it, the new understandings and scattered along the banks, the rhizomes grow. A new place facilitates currere. This journal provides a forum where possibilities are viewed as exciting (Doll, 2009, p. 71). Tentative steps into new spaces are welcomed. Above all, conversation oils the machine, here I can share my thoughts with others who are exploring learning in diverse ways and from non linear perspectives.
\end{abstract}

In this paper I have sometimes presented my personal reflections alongside the texts I am interrogating. With this arrangement I was able to finally see my complex connections more clearly. In other parts, I have described my experience of a new place, Cheonggyecheon stream, as it unfolded for me. This story I have "streamed" through 
the paper, sometimes down the centre of a page. I did this because the place, Cheonggyecheon stream in Seoul, facilitated my rhizomatic thinking and it remained the central thread around which my learning occurred. It runs through both the heart of Seoul and the heart of this paper. Spanning the daylighted stream at intervals are twenty-two bridges, each one unique and symbolic in cultural and historical ways. For me they are metaphors for the learning, the connections, as I bounced from rhizome to rhizome on the sidelines, along the banks of the stream. The bridges were also places to stop, rest, watch the stream and reflect on my learning, places, plateaus.

My interest in how place and pedagogy connect has grown from a love of the landscape and my efforts to capture the essence of place in my painting.

I love to travel to new places and have become increasingly interested in the connections between place and pedagogy.

In this paper I explain how I experienced Cheonggyecheon stream in Seoul during a visit there last year.

I explain this discovering of understanding and uncover a rhizomatic process.

I realized that others explained this way of learning as rhizomatic.

\footnotetext{
I begin to draw on past learnings, rhizomes,

created new rhizomes in order to understand.
}

Others have investigated the pedagogical nature of places that are known and familiar-Sommerville in particular.

How is the pedagogical relationship changed when a place is new, previously unseen and unknown?

Cheonggyecheon is the new place-my stream of thought.

I compare and contrast other texts about connection with place.

It wasn't until I visually illustrated my thoughts that I began to see the clusters and the connections between them.

Warren Sellers

Noel Gough

Margaret Somerville

Deleuze \& Guattari, A Thousand Plateaus

Chaim Soutine

Lloyd Rees

Seoul government official reports on daylighting Cheonggyecheon stream. 
Writing this paper has been an engaging and challenging process. It has taken me many months because I needed to make new connections between previous experiences. I also had to find a new way to write. I wanted the writing to be an exciting and creative experience for me in a way it never had in the past. As I searched through journals, Complicity showcased others who are willing to step outside the conventional and take some creative turns in their writing.

In an editorial for a previous issue of this journal Deborah Osberg, Editor-in-chief, writes of a "claim to address the complex open-endedness of our world and our conceptions of it" (2009, p. iv). She asks "how do we understand the growth of knowledge in a non linear sense?" And draws the reader's attention to what she suggests could be called an emergentist or deconstructionist interpretation of enlarging the space of the possible (2009, p. vi). Importantly for me, she describes the necessity of entering and exploring the space of the impossible. Resonance. And so I enter, albeit tentatively into a generative place, fuelled, as Osberg points out, by conversation and imagination.

I am interpreting rhizomatic theory as an outsider. In the translator's forward of A Thousand Plateaus, Brian Massumi explains how a reader might approach the text, "The question is not: is it true? But: does it work? What new thoughts does it make it possible to think (Deleuze \& Guattari, 1987, p. xv)? In my case, this rhizome has enabled me to see more clearly the learning process I have been engaged in. Prior to exposure to this way of seeing, I felt part of an inexplicable process of learning-a spaghetti networkbut the rhizome provided a way of untangling and seeing differently for me.

My questions on how we learn about places, and what and how places teach us, have built in my mind over many years. Margaret Somerville beautifully illustrates her three key principles of a place-responsive pedagogy by connecting them with her local area, a place she is very familiar with (Somerville, 2010, p. 329). Her text took me to the place also. She explains, "our relationship to place is constituted in stories and other representations; place learning is local and embodied; and deep place learning occurs in a contact zone of contestation." Her words ring true to me as I reflect on the many places I have known well that have been significant in my history, places that I love. I can relate to her perspective when I reflect on the well known. But I have also experienced new places that have resonated with me in a moving way, something instant and powerful, not easily forgotten. And in such places, I have been inspired to learn more, sometimes obsessively. It is specifically the pedagogical connection with a new place that interests me most. When I arrive at a place that I know nothing about, what does it teach me and how does this happen? In this paper I move a little way towards answers to my questions but my search continues.

In his doctoral thesis, Picturing Currere Towards c u r a: Rhizo-imaginary for Curriculum, Warren Sellers explores curriculum in a way I had never imagined. It is his unique search for meaning and he explains this by quoting Grumet: "the root of the word curriculum, is Pinar's term for educational experience, it describes the race not only in terms of the course, the readiness of the runner, but also seeks to know the experience of the running of one particular runner, on one particular track, on one 
particular day, in one particular wind" (Sellers, 2008, p. 87). Here I found a text, different to anything I had ever read, and I connected with it. The writer wasnt expecting it to be read from cover to cover - the reader was encouraged to dip in and out. What a relief! And so I did. The words were not the only texts, drawings and diagrams-images of thinking, were integral and for me, enjoyable. This text was engaging and it made me think. I realised that it is what I seek also, my own understandings in my own time and my own way. A generative connection.

\section{My experience of Cheonggyecheon stream}

Travel guides gave little more than a name and relying on maps in Hangeul with varying English translations, left me with no idea how to locate this place. So I did what I always do when I land in a foreign city-I started walking. It always feels like information overload in such a situation but I know that this way of discovering new places suits me best. Sellers explains that currere is "a way of understanding the complexity and generativity of learning... because learning and meaning are more than a cause and effect dualism" (Sellers, 2008, p. 49).

The teacher provokes, place is the teacher. The learner becomes curious to know and begins to search for understandings. Noel Gough describes the teacher as driving the learning (Gough, 2008). And Warren Sellers writes: "Currere is not so much a method, more a way of living" (Sellers, 2008, p. 140). He further explains..."thinking back to one's own earlier experiences and how that affects present experiences" (p. 142).

As I began to feel the city unfolding around me,

I allowed the sensations to wash over.

The heat, humidity, noise,

the voices, car fumes, diesel bus exhausts, smog, soft greys,

brightly coloured signs with appealing script-balanced and unusual to me.

I began to get the feel of the place.

Somerville (2010) might explain, in her view,

the body is at the centre of our experience of place

Up to this point it feels

like my learning is occurring via sensory stimulation,

but I'm thinking back

to other experiences,

making connections.

I can't help it.

Walking onwards

through the congested city the sound

of water washing over rocks drew me to a bridge rail near the footpath. 


\section{Peering down}

from, what I now know to be Dasangyo Bridge, a surprising view opened up

and I suspected and hoped I had stumbled upon

Cheonggyecheon Stream.

A waterway below stretched in both directions from the bridge

like a thread

through the grey urbanlandscape.

The green plantings

framing the stream

offered a coolness of colour

in contrast to the pounding heat on the footpath.

Stepping down the steep stairway

towards the water was like

sliding into a different world a more natural space where the senses are stimulated and the body begins to relax.

An unhurried mood,

$$
\text { Relief }
$$

from the bustle and noise of

a city in motion

on the streets above.

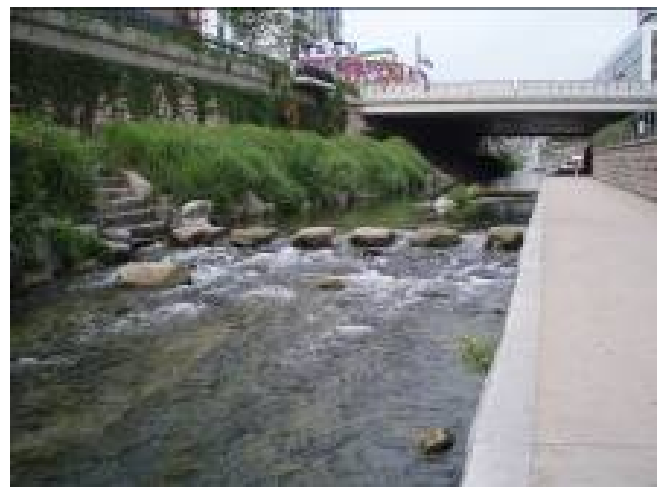

Looking east from below Dasangayo Bridge ${ }^{1}$

\footnotetext{
${ }^{1}$ All photographs by Barbara Chancellor
} 
People were moving slowly down in this cool world.

Many sat silently on seats in the shade of the bridge and stared at the water.

Others wandered by. Initial thoughts swirled around a central core -

I like how this place feels!

The surface under foot changed

from stone to brick

to sand

to concrete

and back to stone.

In this new world,

I could hear water as it spurted

from jets mid stream

trickled over rocks,

then further on gushed through narrow openings, alive with small fish.

Water bubbling and splashing mixed with bird and insect sounds

diminished the traffic above.

The pathway along the streamside wound

between bushes, trees, rushes,

the changing smells

contrasted

with the city fumes

on the street above.

Large natural stepping stones

bridged the stream at intervals and people were crossing on them.

Reflections showed

natural vs. industrial.

The light is softer,

muted,

down near the stream.

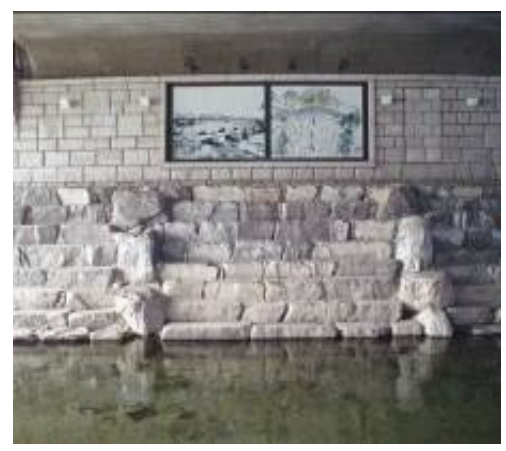

Under a bridge at

Cheonggyecheon Stream.

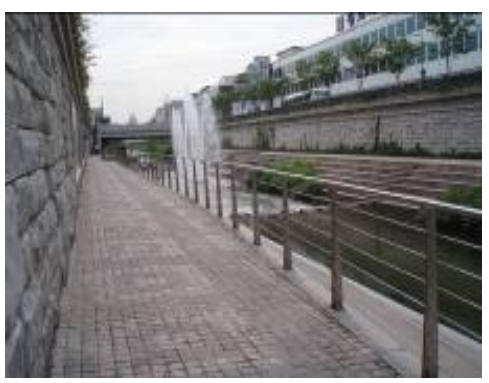

Paved pathway along Cheonggyecheon Stream.

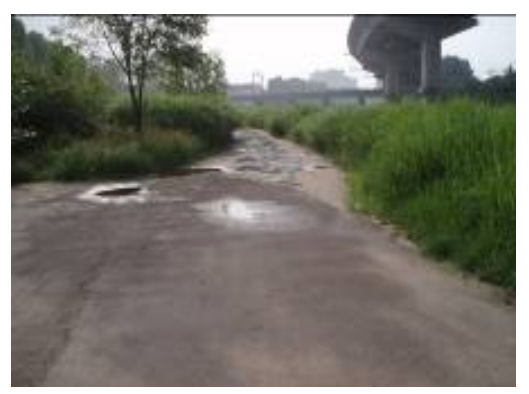

Ephemeral features on pathway at Cheonggyecheon Stream.

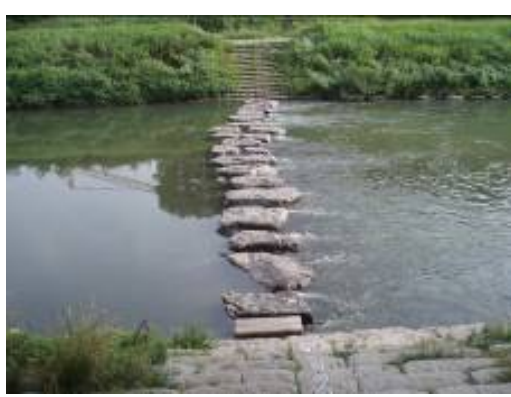

Stepping stones across

Cheonggyecheon Stream. 
My fascination with how pedagogy and place connect was formalised during my doctoral studies when I investigated the ways children were playing in their school playgrounds (Chancellor, 2007). Here I was drawing on a play based pedagogy from the early childhood field to inform my understandings about the learning that was occurring in primary school playgrounds, where children played. These places were well known to the children, but I am now searching to understand the learning that occurs when a place is first experienced.

Alongside is my love of painting in the landscape. This has also involved years of searching for the meaning of place as well as ways of representing it and this involves not only the practice of making pictures but also the research of how other painters have wrestled with the same questions over time.

Notably the works of Australian artist Lloyd Rees, his life long quest to know the meaning of place. His work has long influenced my own practice and over his lifetime of exploring and representing place, he made observations of his own responses to particular places, associating it with a personal dreamtime. Writing about his visit to Ulluru in the winter of 1976,

Now the whole of that area did make me feel the mystery of the Dreamtime. And I was rather surprised to find that I'd never thought of the term to apply to myself, because there is not the slightest doubt that the use of this term has made me think back and realise I undoubtedly have a 'dreamtime'. But it isn't an Australian dreamtime, because that is not possible. When I think back to my beginning in Brisbane, it is all crystal-clear comparatively, and there is no mystery. But when I used to hear old Welsh airs and some of the early French music, my feeling for instance, a very strong one, that I once walked in the Roman Forum. And when I went to the Lascaux grottos, I had a most awesome sensation going into those wonderful caves, with all the beauty of colour; the whole thing had the feeling of stepping back into a dreamtime. And as my French grandfather came from that part of France, it is quite reasonable to think back how many generations of the Burguez (his mother's family) lived around that area. So the Rock had a strange linking up in a way. It didn't make me feel the Aboriginal Dreamtime, but it made me feel the mystery of it, and then sense that I had one of my own. All these things became linked with the mystery of location. (Rees, L. in Free, Renee, 1990, p. 116)

I wonder how this relates with what Canatella describes as the self-givenness of place experience, the unfolding of a life that is an aspect of one's own space and horizon (Canatella, p. 622). This seems to resonate with Somerville's principle of place existing in stories/dreamtimes for indigenous Australians (Somerville, 2010, p. 331). With a degree of similarity, Rees and Somerville describe the experience of becoming part of a place through sensory immersion and in Rees' descriptions it was often a new place. Here is an electric connection with my search. A focus on new.

Rees visited Chatres Cathedral, France in 1959 and 1966. Then in 1973 he spent five days painting there. Writing about this experience,

Those five days spent within the building stand out in my memory as one of the great experiences of my artistic life. For five days I felt I was part of its life. I felt the pulse of it, the constant movement of people, the rhythm of the services and the marvellous 
occasion when the grand organ would make the whole building tremble in unison with its mighty chords (Rees in Free, 1990, p. 38).

My initial experience of Cheonggyecheon was sensory and, over the three days I spent there, I to felt part of its life, although not to the degree experienced by Rees in Chatres Cathedral. Perhaps this is the power of his dreamtime working with the sensory stimulation he describes. Perhaps it is that his learning about this place was deepened through his creation of text-the paintings he worked on while he was physically present, immersed in his search for understanding.

Using texts to teach is not a new idea, nor is using the creation of text to learn. Gough talks about writing to learn (Gough, 2007, p. 211) and although Rees writes about his experiences of place, it is the paintings he created while he was there that are the most powerful and well known of his texts. Somerville also describes the use of stories and other texts as one of her three key principles of a place-responsive pedagogy

At Cheonggyecheon I began to better understand Gough's explanation of Derrida's quote "Il n'y a pas de hors-texte" to mean that "texts are not the sorts of thing that are bounded by an inside and an outside"(Gough, 2008,p. 6). The organic nature of texts is explained by Malaguzzi whose philosophy of early childhood education underpins the pre schools of Reggio Emilia in Italy, "children's learning involves ensuring the benefits that verbal language can derive from non-verbal languages, which reconfirms, in the most general sense, the interfering nature of all languages. But here we must acknowledge that the non-verbal languages actually incorporate many words, feelings and thoughts, many desires for knowing, communicating and expressing themselves, and many means of doing so" (Malaguzzi, 1996). Both he and Gough describe texts in this way where boundaries are blurred.

Chaim Soutine's landscape paintings ${ }^{2}$ from the early 1900's around Paris and outskirts, show me that he could see the organic nature of place. Through his eyes, no one element of landscape is separate, every feature is part of the whole in an active, living way. Through my eyes his texts explain that place is not static and place includes everything as it moves, grows, changes.

Practising a rhizomatic approach, demonstrated to me in the writings of both Warren Sellers (2008) and Noel Gough (2006), I take a pause in the middle to reflect on this process of learning. As I struggled to develop a framework for this paper, I represented my thoughts in a visual manner, scribbled on a piece of A3 paper, and saw a rhizomatic arrangement. Clumps of information, an example, an experience, and between these all the lines of connection. In their text A Thousand Plateaus, Deleuze \& Guattari introduce the rhizome as a richer metaphor than the tree. Through it they show the interconnectedness and possibilities of thinking and encourage non-linear explorations. Between the rhizomes are lines of connections and they describe what these lines look like and how they behave, (Deleuze \& Guattari, 1987, pp. 505-6). My excitement is around seeing meaningful connections between past and present

\footnotetext{
2 Some examples of Soutine's landscape paintings viewable at http://www.abcgallery.com/S/soutine/soutine.html)
} 
experiences and facilitation of new meanings to some of these past learnings. So, uncertainty of process dissipates. This approach has legitimacy and others use it. Its ok.

Gough and Sellers describe "rhizome" as a complex and chaotic form with dynamically complex and continuously changing connections (Gough and Sellers, 2004, p. 10). Accepting the interconnectedness, the blurred fibres between, is essential because this allows the new understanding that they continue to connect in new ways. The map of the internet, used by Gough and Sellers (2004, p. 11) compliments the rhizome because for me some connections are fast, others grow slowly. This approach also explains my spontaneous revisiting of past experiences and then drawing previously unseen connections from them.

No wonder I've had to struggle to make meaning! Each of the clusters of memory I have drawn upon in this paper connect and are entangled in many ways, so attempting to understand pedagogy of place in a linear, deductive way has proved impossible. From my reading on rhizomatic theory the writers have shown me that because we can only draw on the memory clusters we have, we must purposively create new ones in order to further our understandings. Somerville explains "the bits that I gather like a bowerbird are the ones that help me to make these global connections, to interrogate my own histories, producing new assemblages and rhizomatic thought" (2008, pp. 3-4).

Returning to Cheonggyecheon I reflect on Gruenwald's (2003) assertion that place is profoundly pedagogical and it is tempting but, thus far, I was responding to place without understanding it. Gough's (2008) counter to Gruenwald says that places can only become pedagogical through cultural practices that enable or encourage us to attend closely to their multifarious qualities, including not only those that we might consider to be profound but also their more superficial, ephemeral or obvious characteristics (Gough, 2008, p. 2). In a feasibility study commissioned by the Seoul government prior to the commencement of the daylighting project, Kee Yeon Hwag describes the major foci of the proposed project - history and culture. For me this reads like a poem:

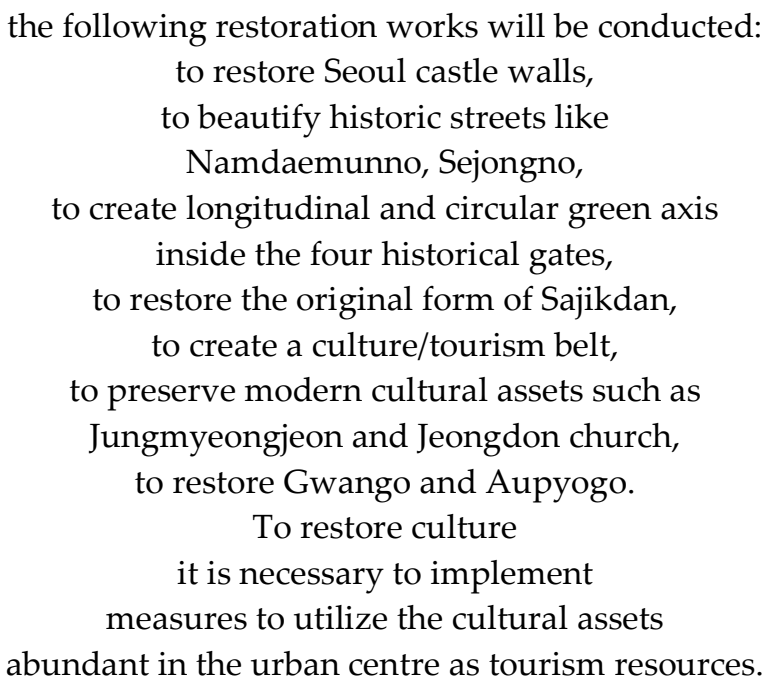

(Kee Yeon Hwag, 2003) 


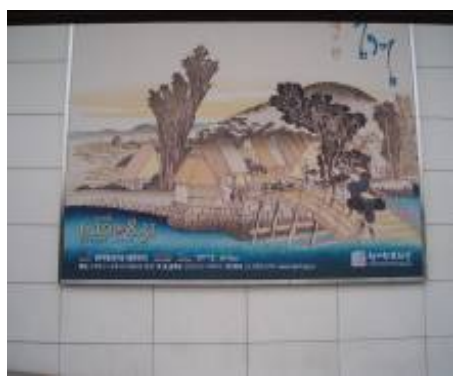

Mural on streamside at Cheonggyecheon

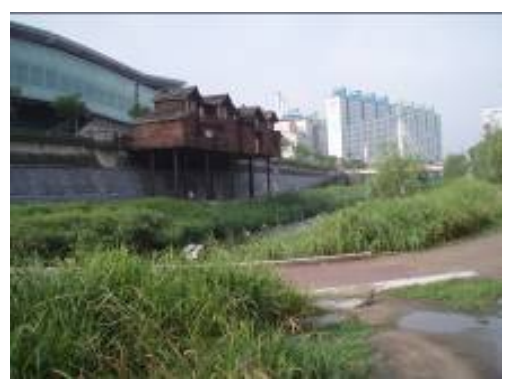

Reconstructed dwellings at Cheonggyecheon.

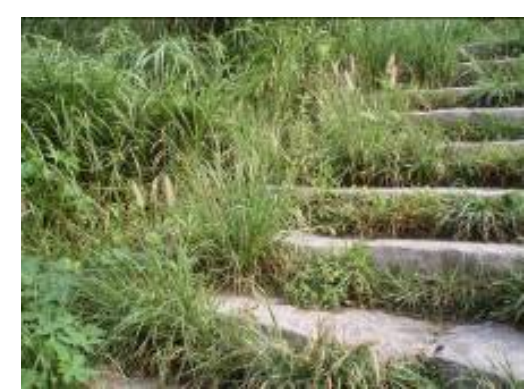

Steps from Cheonggyecheon stream to the city above with grasses

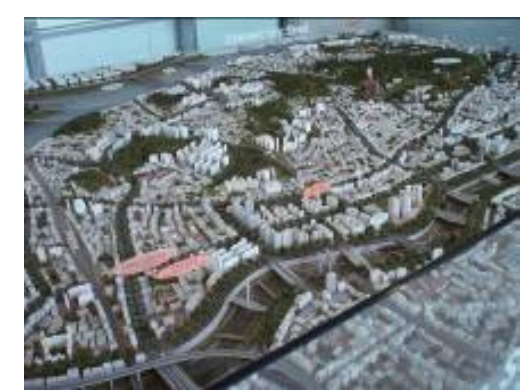

Scale model of the stream restoration photographed

at Cheongyyecheon Museum
A wide range of texts, designed to inform, are positioned from one end of the stream to the other. These became my second teachers, the provocateurs driving the learning - the curriculum facilitating currere.

History of place was acknowledged and celebrated in texts along the stream side in murals and reconstructed buildings.

As sensory experience folded back, close inspection of "texts" occupied my time and they taught me that this daylighting project was a huge investment in time, money and energy. I could also see that it had been strategically planned and probably had further stages to come. 
Gough explains Halsey's proposition that places "become", they are always being invented and fabricated, although they are no less real for being so (Gough, 2008, p. 7). This point comes alive at Cheonggyecheon.

In a 2003 feasibility study, Kee Yeon Hwag states that Seoul city had "shifted its policy paradigm from development to environment, and made harmony with the city paradigm whose focus moved from vehicles to humans and from efficiency to equity, leading social change" (Kee Yeon Hwag, 2003). He continues, "Before restoration works, Cheonggyecheon was covered by $6 \mathrm{~km}$ long and 50-80 m wide...with an elevated highway over the road and $11 \mathrm{~km}$ of intercept sewerage system under the road. More than 168 thousand cars a day running with $62.5 \%$ of them through traffic." He describes the need for repairs to these existing structures at an estimated cost of 100 billion won as the impetus for this massive project as well as the issues of pollution both air and noise for residents and people working nearby. After 47 years spent trying to cover the entire stream with a concrete roadway and matching elevated highway above, the focus moved to creating a new metropolitan life where nature and human culture prosper together. "Now that Korea has reached a level of considerable affluence, environmental protection and a respect for ecology have become major concerns...Through this and other such projects, Seoul will be re-born as a human-oriented environmental city, greatly increasing Seoul's "brand value" (Park Kil-Dong, 2004, p. 11).

The notion of "daylighting" reminds me of a death/re-birth scenario, although the place that died is not the same as the one that is re-born. Cheonnggyechong was buried alive and has now been uncovered and reinvented. This new phase in the life of the stream reflects a public view that Seoul has entered a new era.

The effort to restore the ecology of Cheonggyecheon is based on the concept of three axes: history, culture and nature, showing understanding of the significance of these three themes in building a connection between the people of Seoul today and the daylighted Cheonggyecheon. As Cheonggyecheon is an urban stream running through the centre of the capital east to west, it cannot be practically restored as a natural stream...At the downstream section where Cheonggyecheon and Jungnangsheon Streams join, a swamp and habits for fish and birds will be created so that nature and the city can co-exist. Some parts of the waterside will be restricted from access by citizens, and will be created as green areas for insects and birds...Reservoirs will be built to allow the fish from the Hangang River to move, to serve as habitats for plants and animals... (Park Kil-Dong, 2004, p. 14).

In a report for the Seoul Metropolitan Government of the Cheonggyecheon Restoration Project, Park Kil-Dong describes a "massive campaign" to encourage citizens to use public transport during the restoration (Park Kil-Dong, 2004). As Gavin Hudson explains on the EcoWorldly website, "measures were taken to minimise the impact of dust and noise during demolition as well as the negative impact of businesses in the vicinity of the demolition and construction. In disassembling the expressway, an amazing $95 \%$ of the structure's cement ad $100 \%$ of the steel was carefully salvaged and recycled" (Hudson, 2008). He goes on to note that Cheonggyecheon is "not entirely green. The stream is seasonal. Therefore for most of the year water must be pumped 
from the nearby Han River. The water flows through the stream and back into the Han. However, where there was once a smog-choked expressway, there now stretches a breathtaking and refreshingly pristine greenway. I'll make that trade any day" (Hudson, 2008). Again focusing in on Halsey's proposition of places being invented and fabricated, not only the daylighting of Cheonggyecheon was carefully planned, but also the information available to visitors and locals was detailed and strategic.

It takes little imagination to realise that the daylighting of the stream resulted in significant inconvenience for the residents of Seoul.

On my return to Australia, I decided to purposively grow some new rhizomes to learn more about the history of Cheonggyecheon stream. I did this by accessing documents written both before and during the daylighting. These texts were created to inform about the history and culture of place and, by doing so, reconnect the people in new ways.

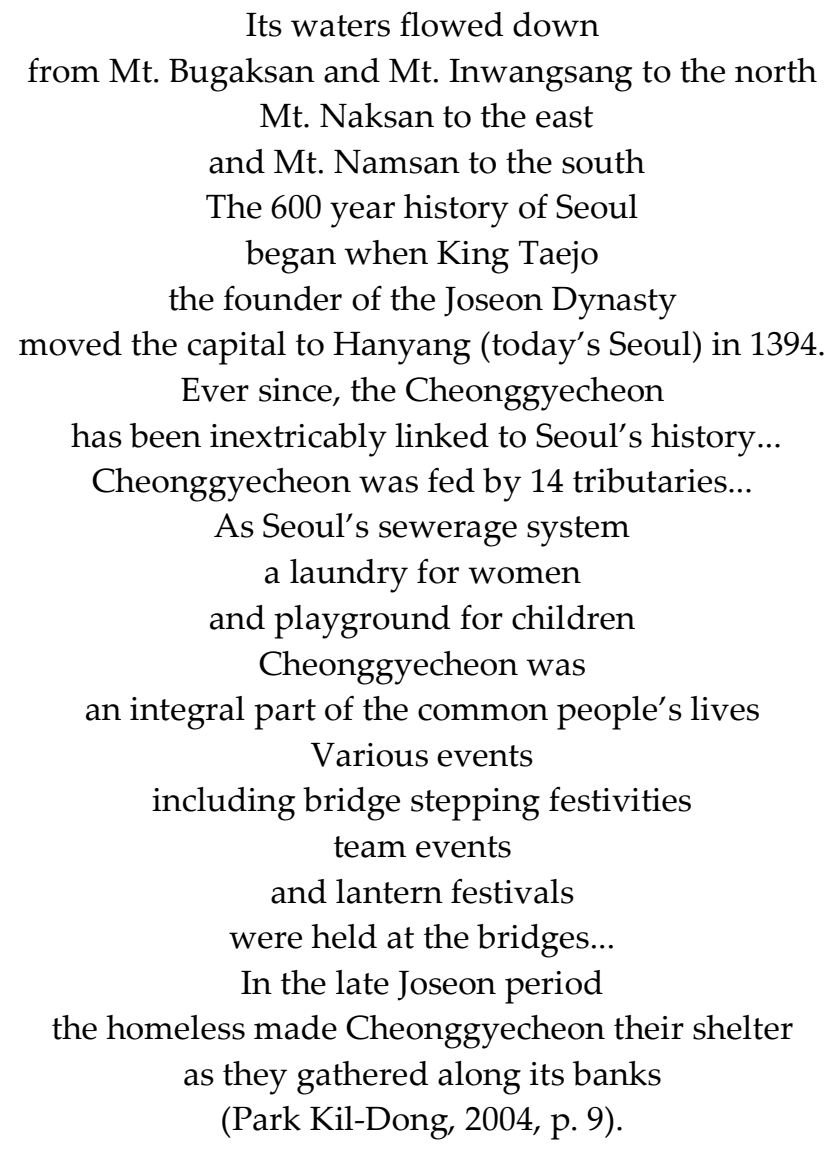

As Hudson explains, much was learned by the people of modern Seoul about their history during the restoration project, "the stream has been the heart of the city, and as it was uncovered archaeologists worked feverishly, fishing for forgotten secrets of ancient life. Ancient coins emerged, Josean period shoes and pottery, a centuries old stone bridge" (Hudson, 2008). 
In relation to understandings of place, Gough describes the notion of every participant being somewhere in particular, we are always "two steps either way" (Gough, 2008, p. 1). Since my return to Australia, I have found many movies on Youtube made at Cheonggyecheon that illustrate what Gough is describing. Importantly, in a new place, I found myself acknowledging that I wasn't of that place-I had no history there prior to my arrival. Also, I see this new place in my own unique way and am drawn to a combination of features that is mine alone. None of the YouTube videos show my ways of seeing Cheonggyecheon. Why would they? My view is unique, "it describes the race not only in terms of the course, the readiness of the runner, but also seeks to know the experience of the running of one particular runner, on one particular track, on one particular day, in one particular wind" (Grumet in Sellers, 2008).

I will finish this jumping from memory to memory, this making connections by telling you about the last place I visited at the stream, the Cheonggyecheon museum. I stumbled upon it accidentally. A modern, purpose built tourist information centre, it included a diversity of texts, from miniature models of the landscape of the stream, to ancient art works, video footage of reconstruction stages, and many other installations. It occurred to me as I wandered around that different texts appeal to different people-a range of pedagogical approaches are needed in order to reach the broadest audience possible. Again, this two steps either way. I was naturally drawn to the area where ancient artworks were displayed, others were sitting watching the video footage and still others seemed engrossed with the scale models of ancient and modern Seoul.

I pause to ask, what has happened here? Writing is helping me to understand the learning process I am actively engaged in. Currere. Warren Sellers writes, currere is not so much a method, more a way of living (Sellers, 2008, p. 140). He further explains...thinking back to one's own earlier experiences and how that affects present experiences (p. 142).

In this paper I have explored my experience of a new place and its generative impact, fuelling the search for understanding of place based pedagogy. No conclusions have been reached. The swirling mix of ideas has been given a stir. Sellers describes his journey, "regardless of context, I am running a course" (Sellers, 2008, p. 278). For me, including new places in my course is generative and has in this particular instance, pushed me in a new and exciting direction where I began to see that a rhizomatic way of thinking can explain my learning process. Thankfully, the desire to learn continues. I dont want the run to end. This "folding back upon past experiences and understandings" has helped me explore the links between pedagogy and place as I feel and see it at this point in time, from my "somewhere in particular".

In this paper I have experimented with a new way of writing. No longer stimulated by traditional academic prose, I am searching for a way to explain my thought processes as I explore connections between place and pedagogy. As I begin to see how the metaphor of rhizome encapsulates my thinking my challenge is to represent this in the texts I create.

As the run continues, the runner is constantly changed by what she experiences. Whilst a snapshot can be taken at any given time, the next picture will be changed. This 
paper is one snap, a picture of my linking pedagogy and place but it has changed, is changing, will continue to change. Currere is a reflexive cycle in which thought bends back upon itself and thus recovers volition (Grumet, 1976 in Sellers, 2008, p. 87). The texts created by Gough, Sellers, Somerville, Malaguzzi, Soutine and Rees have all been generative for me and they have each changed this runner, at the same time fuelling the desire to keep running. Jerome Bruner on visiting the preschools of Reggio Emilia wrote,

The most profound way in which respect between human beings shows itself is by taking to heart, taking seriously the meaning that each of us seeks to create from our experience of the world: the world of things and the world of people alike. The truest courtesy in human interactions and pedagogy is to help others discover what their experiences mean in their minds and hearts. And then helping them find richer, fuller, more communicable meanings. (Bruner in Malaguzzi, 1996, p. 117).

I now seek the "two steps either way" described by Gough (2008) of others interested in how new places and pedagogy connect because their comment is likely to be generative for me. As Bruner did, I also recognise the importance of others in my search for understandings. This journal has provided me an opportunity to engage in "the play of thought" (Phelan, 2004, p. 15) and share my thinking.

The notion of "enlarging the space of the possible around what it means to educate and be educated" the words of founding co-editors of this journal Renata Phelps and Brent Davis (Davis \& Phelps, 2004) are inspiring. They are welcoming and supportive and allow the possibility of playful writing. As we toil in our search for knowledge, sharing our voices and valuing discussion, the space of the possible is greatly enlarged. On this note I will conclude this paper about pedagogical possibilities of new places and I hope I have "goaded" or perhaps "created space of unsettlement" with this explorative piece of writing. So when considering the pedagogical nature of place, has the new facilitated currere? In this particular case, in this particular time, this has occurred via a rhizomatic process where I have made connections between many past experiences (see Figure 1). In order to clarify my understandings I have needed to search for new information, grow new rhizomes along the way. Writing this paper has been an enjoyable learning experience where I have allowed myself some creative freedom as I played with thought and structure. Surprisingly, I am not relieved to finish but instead see this as the first step in a new direction for me, a new beginning. 


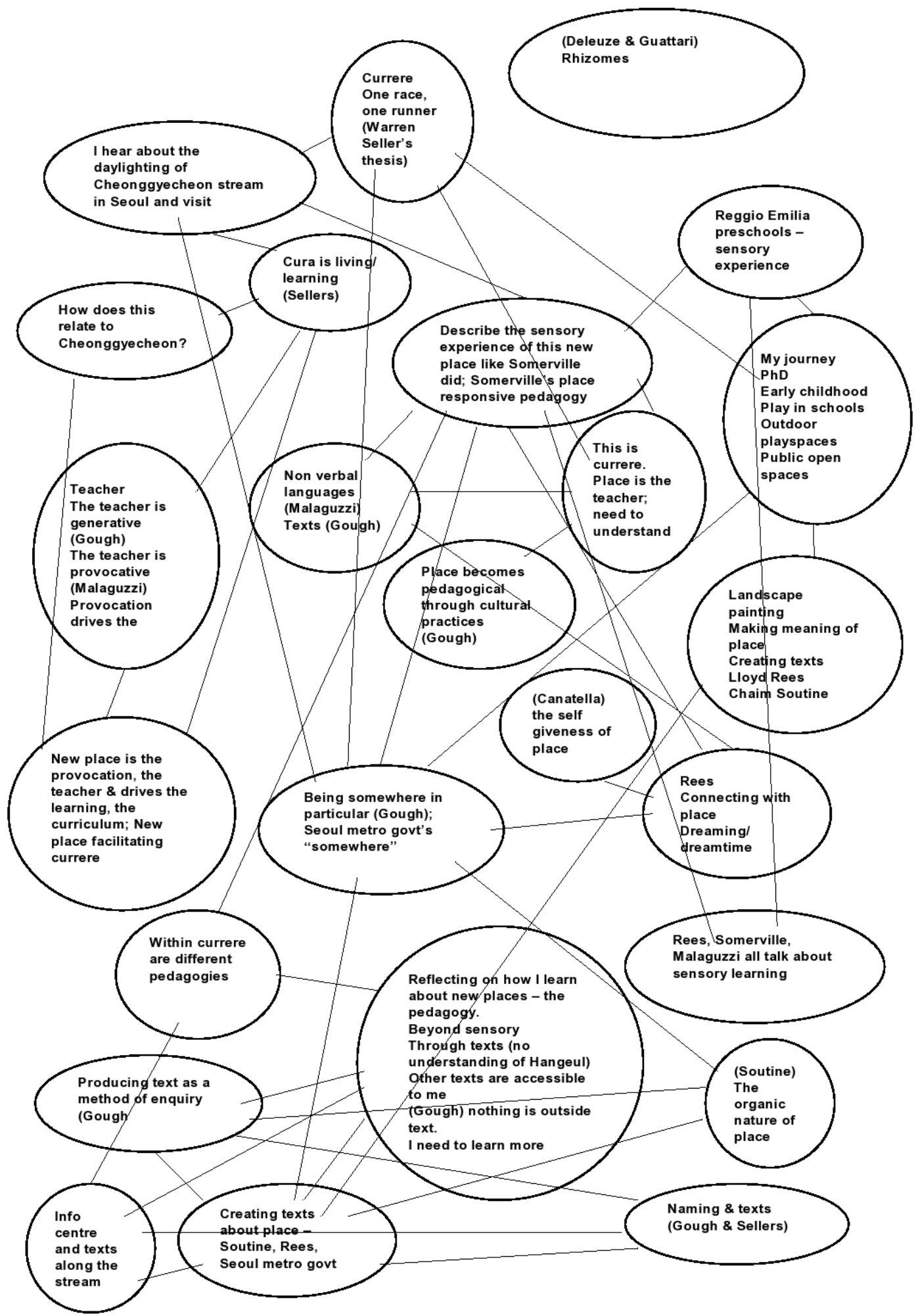

Figure 1. Using rhizome to find new connections between previous experiences. 


\title{
References
}

Cannatella, H. (2007). Place and being, Educational Philosophy and Theory, 39(6): 622-632.

Chancellor, B. (2007). The changing face of play in Australian primary school playgrounds, Doctoral Thesis, RMIT University, Melbourne, Australia.

Davis, Brent \& Phelps, Renata. (2004). Complicity: An International Journal of Complexity and Education, 1(1):1-7.

Deleuze, G. \& Guatarri, F. (1987). A thousand plateaus, Translation by Brian Massumi, University of Minnesota Press, Minneapolis.

Doll, W.E. (2009). Afterword, Complicity: An International Journal of Complexity and Education, 6(1): 71-4.

Free, R. (1990). Lloyd Rees, the last twenty years, Craftsman House, Roseville, New South Wales.

Gough, N. (2006). Shaking the tree, making a rhizome: towards a nomadic philosophy of science education, Educational Philosophy and Theory, 38(5): 625-645.

Gough, N. (2007). Crime fiction and educational inquiry: reading, writing and intertextual play, Quarterly Journal of Educational Innovations, 6(21): 208-235.

Gough, N. (2008). Essay prepared for Place Studies in Australia: An interdisciplinary inquiry into landscapes and learning (working title; MUP Academic Monograph Series). Draft 12 May 2008.

Gough, N. \& Sellers, W. (2004). Re/de/signing the world: Postructuralist deconstruction and reality in outdoor/environmental educational research. Paper presented at International Outdoor Education Research Conferenece, La Trobe University, Bendigo, Australia.

Gruenwald, D. A. (2003). Foundations of place: a multidisciplinary framework for place-conscious education. American Educational Research Journal, 40(3): 619-654.

Hudson, G at http://ecoworldly.com accessed 2008/06/04

Kee Yeon, H. (2003). Feasibility study and master plan of Cheonggyecheon restoration, Mid-term report, 2003A. Jan., Seoul Development Institute.

Malaguzzi, L. (1996) in Catalogue of the exhibition, The hundred languages of children, narrative of the possible, municipality of Reggio Emilia infant-toddler centres and preschools, Italy.

Osberg, D.C. (2009). Enlarging the space of the possible around what it means to educate and be educated. Complicity: An International Journal of Complexity and Education 6(1): iii-x.

Park Kil-Dong. (2004). Cheonggyecheon restoration project, Seoul Metropoliton Government, Korea. Available at http://www.csur.t.u.-tokyo.ac.jp/ws.

Phelan, A. M. (2004). Rationalism, complexity science and curriculum: a cautionary tale, Complicity: An International Journal of Complexity and Education, 1(1): 9-17.

Sellers, W. (2008). Picturing currere towards cura: rhizo-imaginary for curriculum, Doctoral Thesis, Deakin University, Melbourne.

Somerville, M. J. (2010). A place pedagogy for "global contemporaneity", Educational Philosophy and Theory, 42(3):326-344.

\begin{abstract}
About the Author
Barbara Chancellor, PhD., is a Senior Lecturer in the School of Education at RMIT University, Melbourne. Her research interests have linked early childhood education philosophy of play based learning with the learning that occurs in schools, particularly in outdoor spaces. This has merged with research about design implications for creating public play spaces for children with high affordances for play. Her love of landscape painting has increasingly informed her research and has brought her to her current interest in pedagogy of place. She can be contacted at barbara.chancellor@rmit.edu.au.
\end{abstract}

(c) Copyright 2010. The author, BARBARA CHANCELLOR, assigns to the University of Alberta and other educational and nonprofit institutions a non-exclusive license to use this document for personal use and in courses of instruction provided that the article is used in full and this copyright statement is reproduced. The author also grant a non-exclusive license to the University of Alberta to publish this document in full on the World Wide Web, and for the document to be published on mirrors on the World Wide Web. Any other usage is prohibited without the express permission of the authors. 